\title{
The benefits of aggressive traits: A study with current and former street children in Burundi
}

\author{
Anselm Crombach ${ }^{\mathrm{a}, \mathrm{b}, \mathrm{c}, *}$, Thomas Elbert ${ }^{\mathrm{a}, \mathrm{b}, \mathrm{c}}$ \\ a Department of Psychology, University of Konstanz, Box D23, 78457 Konstanz, Germany \\ b Department of Psychology, University Lumière of Bujumbura, Burundi \\ ${ }^{c}$ Vivo International e.V., Germany ${ }^{1}$
}

Keywords:

Burundi

Violent behavior

Resilience against PTSD

Street children

Reactive aggression

Appetitive aggression

\begin{abstract}
A B S T R A C T
Aggressive behavior in children and youths is commonly associated with exposure to violence and maltreatment. Consequently, aggressive behavior has often been explained as a form of reactive behavior in response to violence-inflicted mental suffering. However, perpetrating violence can become appealing, fascinating and exciting, i.e., may acquire appetitive, self-rewarding aspects. We postulated that this appetitive form of aggression reduces the vulnerability for developing Posttraumatic Stress Disorder (PTSD) in insecure and violent environments. Furthermore we investigated the extent to which reactive aggression and appetitive aggression account for recent violent behavior in children and youths. We conducted semi-structured interviews in a sample of 112 children and youths $\left(M_{\mathrm{age}}=15.9\right.$ years $)$ recruited from the streets, families and a residential center for vulnerable children in Burundi. We investigated the cumulative exposure to traumatic events and to domestic and community violence, assessed the recently committed offenses, the severity of PTSD symptoms, and the potential for reactive and appetitive aggression. Reactive aggression was positively related to PTSD, whilst appetitive aggression was negatively related to PTSD. Children higher in appetitive aggression were also more likely to display violent behavior. These results suggest that an appetitive perception of violence may be an useful adaption to insecure and violent living conditions reducing the vulnerability of children for trauma-related mental disorders. However, positive feelings experienced through violent or cruel behavior are also an important risk factor for ongoing aggressive behavior and therefore need to be considered in prevention strategies.
\end{abstract}

\section{Introduction}

In Bujumbura street children call themselves "abatimbayi". [...] That means "persons who support everything, who are not afraid of anything, persons with cold blood."

Translation by the authors; Nsengiyumva, 2010, p. 6

Fifty years ago, Curtis (1963, p. 386) expressed the concern that “abused and neglected children would become tomorrow's murderers and perpetrators of other crimes of violence". Since that time, substantial evidence has accumulated demonstrating that experiencing violence is related to expressing violence (e.g., Elbert, Rockstroh, Kolassa, Schauer, \& Neuner, 2006;

* Corresponding author at: Department of Psychology, Clinical Psychology and Clinical Neuropsychology, University of Konstanz, Box D23, 78457 Konstanz, Germany.

1 NGO, www.vivo.org. 
Weaver, Borkowski, \& Whitman, 2008). In the Western countries, a large proportion of homicide offenders come from unfavorable home environments and up to $80 \%$ of subjects within delinquent samples report exposure to violent acts during their childhood or adolescence. Commonly, it is assumed that the subsequent aggressiveness results as a direct reaction from an explosive, uncontrolled and impulsive response to perceived threats or provocations in the environment. The underlying emotions of this reactive or relieving form of aggression are fear, anxiety and anger. The fundamental function of this type of aggression is to alleviate the tension and discomfort experienced with these emotions, and to eliminate or reduce the perceived danger or damage (Fontaine, 2007; Kempes, Matthys, de Vries, \& van Engeland, 2005; Weierstall \& Elbert, 2012).

However, it has become increasingly obvious that perpetration of violence is experienced very differently than exposure to violence and is not necessarily linked to a purely aversive emotional state. Deliberately aggressive thoughts and behavior can be intrinsically rewarding (Elbert, Weierstall, \& Schauer, 2010). In fact studies with former child soldiers, combatants, and genocide offenders have revealed that the perpetration of violence is often experienced as exciting, appealing, and fascinating (e.g., Weierstall, Bueno Castellanos, Neuner, \& Elbert, 2013; Weierstall, Schaal, Schalinski, \& Elbert, 2011). Many offenders reported the development of appetitive aggression, i.e., the perpetration of violence and/or the infliction of harm upon a victim for the purpose of experiencing violence-related enjoyment. This appetite for aggression can even result in risk-seeking behavior, which motivates individuals to look for opportunities to act out violently. Growing up in a culture of cruelty may strongly imprint and alter neurophysiological pathways of processing violent cues and emotional responses in former child soldiers, even years after returning to a peaceful society (Elbert et al., 2006, 2010). In the insecure and dangerous environment of combat, appetitive aggression seems to constitute a potential adaption enabling individuals to cope with violence and atrocities around them. As recent studies indicate, individuals capable of engaging in higher levels of appetitive aggression were more resilient against developing symptoms of Posttraumatic Stress Disorder (PTSD). This protective factor can counter only a certain load of exposure to traumatic stressors. When exposure becomes too severe, even individuals with a high level of appetitive aggression will suffer from PTSD (Hecker, Hermenau, Maedl, Hinkel, et al., 2013; Hecker, Hermenau, Maedl, Schauer, \& Elbert, 2013; Weierstall et al., 2013, 2011; Weierstall, Schalinski, Crombach, Hecker, \& Elbert, 2012).

So far studies assessing appetitive aggression have focused almost exclusively on male populations that were heavily involved in the perpetration of violence. The majority of the participants were ex-combatants and had severely injured at least one other individual and many had even frequently killed or tortured. They were all adults at the time of the investigation. We assume, however, that the development of appetitive aggression is not limited to these extreme populations but is also present in less dangerous and violent environments. An insecure and violent environment not only provokes reactive aggression but also seems to foster a trait for appetitive aggression. Becoming a perpetrator instead of a victim, winning fights and thereby regaining a feeling of control in insecure and dangerous living conditions such as in the streets, could be the prerequisite for the activation of this trait. Feelings of power, control, and effectiveness in violent situations lead to the enjoyment of violence and a craving for more.

In this study we want to test if the development of appetitive aggression in children and adolescents growing up in insecure environments strengthens their resilience against PTSD. We also wanted to assess the positive emotions toward aggression and their role in maintaining violent behavior. As physical violence is more common in males, and appetitive aggression has only been assessed so far in male combatants, we focused in this study on boys and young men (Elbert et al., 2010).

Reactive aggression has been consistently linked to PTSD. Research suggests that this is due to the emotional dysregulation, i.e., the diminished emotional control, affective instability, and impulsive angry reactions that is associated with PTSD (Marsee, 2008). Furthermore the ability to adequately process social information seems to be diminished in individuals affected by trauma-related mental disorders. Everyday cues are more often perceived as threatening, hence leading to fearful and angry reactions (Ford, 2002). In children and adolescents evidence for this relation has been provided by several studies showing that effects of experienced violence during childhood on aggressive behavior were amplified by the presence of PTSD symptoms (Moretti, Obsuth, Odgers, \& Reebye, 2006; Wood, Foy, Layne, Pynoos, \& Boyd, 2002) and that children who had experienced traumatic incidences reported more reactive aggression than children without traumatic life events (Connor, Doerfler, Volungis, Steingard, \& Melloni, 2003). Moreover, regular exposure to violence at home, in school or anywhere else in the community amplifies not only PTSD symptoms but also the probability of aggressive behavior in children and adolescents (Flannery, Wester, \& Singer, 2004; Shields \& Cicchetti, 1998, 2001; Turnera, Finkelhorb, \& Ormrodb, 2006).

For the assessment of our hypotheses we decided to study male children and adolescents growing up in the post-conflict country Burundi, which is situated in Eastern Africa. In 2006 a civil war that shook the whole country for 13 years ended. Today, the population still suffers from its consequences (e.g., severe poverty, violence in daily life). Constant feelings of insecurity arise from lack of food and politically motivated killings. The latter are often committed on a communal level by ordinary people (Human Rights Watch, 2012). In the Burundian culture violence is widely accepted as a means of punishment for thieves or as a means of authority in educational matters. Children risk being punished by beating every day in school, at home, or on the streets (Sommers, 2013).

Although the vast majority of children and adolescents in Burundi have been exposed to violence, war events, and insecurity (Jordans, Tol, Komproe, Susanty, \& Vallipuram, 2010; Warf, Eisenstein, \& Stahl, 2009), we aimed to include children from different backgrounds to ensure sufficient variance in both exposure to violence and the committing of violence for the scientific questions of our enquiry. Hence, we included children and adolescents growing up in families with different 
social backgrounds in Bujumbura. The age range of this part of the sample was adjusted to children living in a residential center for vulnerable children including those who had lived in the streets. For the purpose of this study we defined former street children as all children who had been exposed to the dangers of the streets and had to struggle to survive on their own. We hypothesized that these children were more exposed to and affected by violence than the ones still living in their families. Furthermore we also included current street children. Research and reports on street children suggest that they are continuously exposed to high-risk situations. Many suffered and continue to suffer from famine, natural disasters, and/or orphanhood caused by AIDS, social violence, or war. They have limited access to adequate food, shelter, clothing, and medical care. In war-affected countries in particular, street children most likely survived internal displacements, flight, and exposure to combat situations. Many have already faced violence, abuse, and neglect at home. In the streets, the children often suffer maltreatment, intimidation, robberies, and sexual and physical assaults. Most of them have to pass violent initiation rituals to become accepted by the other, older street children. Additionally, they risk being chased, beaten up, and sometimes even imprisoned by the police (e.g., Pinheiro, 2006; Thomas de Benitez, 2007).

At the same time street children are also involved in committing violence. Older boys often take advantage of the younger children in the streets (Aptekar, 1994), poverty forces them to take part in robberies (Bop, 1990), or they need to defend their social status within a group of street children (Nsengiyumva, 2010). As children age into teenagers and young men in the streets, they are forced into criminal activity because they are no longer considered cute and helpless but rather dangerous. Hence begging money from the public becomes more difficult (Thomas de Benitez, 2007). Therefore, we expected the current street children to be simultaneously the most affected by experienced violence and the most inclined to commit violent offenses.

\section{Methods}

\section{Participants}

The participants in this study were 112 Burundian boys and young men living in the capital Bujumbura with an age range of 11-24 years. Inclusion of boys from different social backgrounds in this study ensured variance of exposure to violence. There were four groups: (a) current street children ( $n=15)$; (b) family children $(n=15)$; (c) former street children ( $n=32$ ); and (d) former family children $(n=50)$. In order to obtain a representative sample of current street children, three different places in Bujumbura were selected to contact and invite them randomly to participate in the study. The current street children were compared to family children who grew up and still lived with their families and had no street experience. The families invited to participate were chosen randomly. The quarters, streets, and houses were approached in a random order. For each quarter, only one child was studied in order to get a representative sample for the city of Bujumbura and to include families with different social backgrounds. Family children who had reported street experience $(n=2)$ and with mental disabilities $(n=1)$ were excluded from further analysis. The remaining 82 children were recruited from a residential center for vulnerable and former street boys. Out of these boys, 32 were considered to be former street children because they had spent part of their lives on the streets. The other 50 had also lived through difficult circumstances but had never spent time on the streets. Hence they were former family children. One child was excluded from the analysis due to epilepsy. All four groups were selected so that they had a comparable age range.

The Ethical Review Board of the University of Konstanz approved the study, and the University Lumière of Bujumbura assisted with the implementation. All participants gave their informed consent. For participants under the age of 18 , the children and the legal guardians, if known, gave informed consent. Whereas boys in the center profited later from restructuring of the center to improve communication between educators and children, therapies, and other supporting activities, the children in the streets and in the families received a financial compensation of 5,000 fbu $(\approx 2.86 €)$.

\section{Procedure}

The assessment was conducted from the beginning of January until April 2011 in the center and from March 2011 until June 2011 with the street and family children. Two German psychologists (one of them A.C., living in Bujumbura before and during the period of the assessment and working as the supervising psychologist of the residential center) with clinical training and work experience in East Africa conducted the interviews with the help of two local interpreters. The interpreters had been trained as co-investigators in the relevant concepts of mental disorders and translated between French and Kirundi. In order to standardize the form of assessment and achieve a high inter-rater reliability, the interviewers had practiced in joint interviews. To guarantee a precise translation, different interpreters translated all instruments from a validated English or French version to Kirundi and back into English or French. The results of the translation procedure were discussed in detail with the interpreters before the beginning of data collection. To guarantee confidentiality, the interviews were conducted in quiet, private locations in the residential center, at home, at the Red Cross Burundi, and in schools. Furthermore the interviewers ensured that no other person was present or could listen to the interviews. The children were assured that everything they said during the interview was confidential and that there would be no negative consequences or punishment for whatever information was given. In addition to the interviews the main researcher observed the behavior and performance of the children in their daily activities, school, and joint playing. The study on aggressive behavior was part 
of a bigger project that assessed the mental health situation of the children in the residential center and of street children as part of overall consideration for possible interventions.

\section{Materials}

Socio-demographics. The participants were asked about their background and their current social situation. This included questions about their age, education, contact with their family, time spent within the center, time spent on the streets, and physical health complaints during the past four weeks (i.e., cough/cold, stomach pain, tuberculosis, headache, malaria, pain, diarrhea, fever/shivering, skin rush/scabies, and vomiting; following Neuner et al., 2008).

Domestic and Community Violence Checklist. In order to assess the exposure to violence of the participants, they were asked 37 items about their experience with violence (following Hermenau et al., 2011). The events in the checklist range from small events like being pinched or slapped to very frightening events like being injured with a weapon or sexually abused. The checklist includes physical, psychological, and sexual violence; neglect; and witnessed violence. For every event the participants were asked if they had experienced the violence once or regularly (at least once per month for three consecutive months) and if they had experienced this violence recently, specifically during the past three months.

University of California Los Angeles (UCLA) PTSD Index for children and adolescents. The UCLA PTSD Index for children and adolescents (Steinberg, Brymer, Decker, \& Pynoos, 2004) was used in interview form to assess the exposure to traumatic events and the severity of symptoms of PTSD. The latter is assessed based on the frequency of symptoms reported by children. The occurrence of each DSM-IV symptom within the last month is scored on a scale from none of the time (0) to most of the time (4). Thus an overall PTSD severity score can be calculated by summing up the symptom scores, which results in a maximum possible score of 68. A PTSD diagnosis was assumed if the DSM-IV criteria were fulfilled including impairment in the daily functioning of the children in response to traumatic stress. The UCLA PTSD Index shows good psychometric properties and has been successfully utilized and validated in low-income conflict regions (Catani, Jacob, Schauer, Kohila, \& Neuner, 2008; Elbert et al., 2009; Hermenau et al., 2011; Shaw \& Harris, 2003). Interrater reliability was assessed by independently rating the same child in parallel, i.e., when both interviewers were present. The intraclass correlation of .99 $(p<.001)$ indicated a high agreement among the interviewers.

Offense checklist. The committed offenses of the children were assessed with an offense checklist, constructed after the model of the traumatic event checklist. The list consists of 18 items ranging from "I hit back when being attacked" to "I have hurt another person severely/killed another person". We recorded whether the offense was committed at all in their lives, and secondly whether this was committed in the last 3 months. The sum score represents the number of different offense types, as opposed to number of offenses, which is hard to quantify by self-report. Scores range from 0 to 18 .

Reactive Proactive Aggression Questionnaire. The potential for reactive aggression was assessed with the 11 reactive items of the Reactive-Proactive Questionnaire (Raine et al., 2006). The children were asked how often they have exhibited a specific aggressive behavior. They had to choose between never (0), sometimes (1) and often (2). The sum score of the reactive scale showed good psychometric properties and validity in a sample of American youths and has been successfully used in a study with Tanzanian children in a residential center (Hermenau et al., 2011). The sum of the points assigned to the answer represents the reactive aggression and ranges from 0 to 22. Interrater reliability was assessed by independently rating the same child in parallel, i.e., when both interviewers were present. The intraclass correlation of .99 $(p<.001)$ indicated a high agreement among the interviewers.

Appetitive Aggression Scale for Children. The children's propensity to perpetrate aggressive acts was assessed using the Appetitive Aggression Scale for Children (AAS-C) that was based on the Appetitive Aggression Scale for Combatants (AAS; Weierstall \& Elbert, 2011), a semi-structured interview that has been validated with over 1,600 ex-combatants and has been proven to have good psychometric properties. It contains questions regarding the appetitive perception of aggression. The items are based on the definition of the instrumental aggression subtype according to Vitiello and Stoff (1997) and the International Classification of Diseases 10 (ICD-10; World Health Organization, 2008) addiction criteria. Further items were compiled on the basis of interviews with perpetrators about the appetitive experience of perpetrating aggressive acts. In the AAS-C the items were asked in regard to the last month or if the children thought the item still applied to them. Most of the items of the original version for combatants were rephrased to adapt them to a non-combatant setting and to facilitate the language for the children (e.g., Item 4 of the AAS: "Do you feel powerful when you go to a fight?" was rephrased to: “...if you fought with others, you mostly expected to win?"; Item 15 of the AAS: "When you fight, do you stop caring about whether you could be killed?" was rephrased to: “......sometimes you wanted to fight/watch a fight, even though you knew that you could be hurt?"). An item of the AAS concerning experiences of sexual arousal when attacking someone was replaced with an item that asked about the satisfaction of imagining someone being hurt. This new item was considered more appropriate for the children. We replaced item 12 of the AAS ("Do you know what it is like to feel the hunger/thirst to fight?") with two items (“...sometimes you really wanted to fight?" and "... if you imagined going to fight, you felt an urge for it in your body and you wanted to unleash it?"), including only the higher scoring item for the individual child in the sum score. Additionally 
we added two items to the AAS-C that were not in the AAS (“...you felt strong and powerful because you attacked someone?" and “...you teased others so they would fight against you?”). Each item is scored on a five-point Likert scale ranging from 0 (I totally disagree) to 4 (I totally agree). The total sum score of the 17 -item scale represents the appetitive perception of aggression and ranges from 0 to 68. Cronbach's Alpha coefficient as a measure for reliability of the scale was .80. In a principal-axis factor analysis, all items loaded statistically significantly onto a single factor accounting for $23 \%$ of the total variance. Interrater reliability was assessed by independently rating the same child in parallel, i.e., when both interviewers were present. The intraclass correlation of $.99(p<.001)$ indicated high agreement among the interviewers.

\section{Data analysis}

The statistical analysis was carried out using SPSS 20.0 (IBM Corporation, Armonk, New York, USA). For assessing group differences a MANOVA was calculated. The different effects of aggressive subtypes on PTSD and on recently committed violence were assessed with multiple linear regression models.

\section{Results}

\section{Description of participants}

Table 1 presents the demographic data of the 112 participants separately for the four groups: the former family children and the former street children, the street children and the family children. As expected, the street children had spent significantly more time in the streets than the former street children within the center $\left(t_{(16.32)}=-2.98, p=.009\right)$, and they had successfully completed fewer school grades than the other three groups (all $z<-2.70$, all $p<.007$ ). Twenty-three percent of all the children who no longer lived with their families had left their homes because of maltreatment or because they were exploited as workers.

\section{Group differences}

We calculated a MANOVA to assess our hypothesis that street children and former street children had been exposed to more traumatic events, more regular violence and insecurity during theirs lives, and suffered more from symptoms of PTSD. At the same time, we assessed the differences in perpetrated offenses and the different forms of aggression. The variables used were the traumatic life events list, the sum of PTSD severity of the UCLA PTSD Index, the sum score of the regularly experienced violence of the Domestic and Community Violence Checklist, the number of recent offenses, the reactive aggression score of the Reactive-Proactive Aggression Questionnaire, and the appetitive aggression sum score of the AAS-C. The statistical analysis revealed highly significant differences with strong effect sizes on the multivariate level $\left(F_{(18,291.81)}=5.20, p<.001, \eta_{p}^{2}=.23\right)$ and on the univariate level for the PTSD severity $\left(F_{(3,108)}=5.88, p=.001, \eta_{p}^{2}=.14\right)$, traumatic life events $\left(F_{(3,108)}=12.22, p=.001\right.$, $\left.\eta_{p}^{2}=.25\right)$, regularly experienced violence $\left(F_{(3,108)}=14.09, p<.001, \eta_{p}^{2}=.28\right)$, recent offenses $\left(F_{(3,108)}=20.15, p<.001, \eta_{p}^{2}=.36\right)$

Table 1

Demographic data.

\begin{tabular}{|c|c|c|c|c|}
\hline & $\begin{array}{l}\text { Former family children } \\
\text { in the center } \\
(N=50)\end{array}$ & $\begin{array}{l}\text { Former street children } \\
\text { in the center } \\
(N=32)\end{array}$ & $\begin{array}{l}\text { Street children } \\
(N=15)\end{array}$ & $\begin{array}{l}\text { Children living in } \\
\text { families } \\
(N=15)\end{array}$ \\
\hline $\begin{array}{l}\text { Age, years, mean (SD) } \\
\text { [range] }\end{array}$ & $\begin{array}{l}15 \\
.5(3.1)[11-23]\end{array}$ & $\begin{array}{l}16 \\
.6(2.6)[11-21]\end{array}$ & $\begin{array}{l}16 \\
.2(3.2)[12-24]\end{array}$ & $\begin{array}{l}15 \\
.7(3.1)[11-22]\end{array}$ \\
\hline $\begin{array}{l}\text { Age at the time of } \\
\text { leaving family, years, } \\
\text { mean (SD) [range] }\end{array}$ & $\begin{array}{l}11 \\
(3.2)[5-17]\end{array}$ & $\begin{array}{l}9 \\
.9(2.7)[5-15]\end{array}$ & $\begin{array}{l}10 \\
.4(3.5)[4-16]\end{array}$ & $14(0)[14]^{\mathrm{b}}$ \\
\hline $\begin{array}{l}\text { Time spent on the } \\
\text { streets, months, } \\
\text { mean (SD) [range] }\end{array}$ & 0 & $\begin{array}{l}18 \\
.7(20.3)[0.1-84]\end{array}$ & $\begin{array}{l}57 \\
.8(48.9)[1.5-156]\end{array}$ & 0 \\
\hline $\begin{array}{l}\text { Time spent in the } \\
\text { center, months, } \\
\text { mean (SD) [range] }\end{array}$ & $\begin{array}{l}50 \\
.3(26.4)[3-120]\end{array}$ & $\begin{array}{l}60 \\
.3(24.1)[7-120]\end{array}$ & $-{ }^{a}$ & $-a^{a}$ \\
\hline $\begin{array}{l}\text { Orphaned children, No. } \\
(\%)\end{array}$ & $15(30 \%)$ & $\begin{array}{l}11 \\
(34.4 \%)\end{array}$ & $\begin{array}{l}5 \\
(33.3 \%)\end{array}$ & $\begin{array}{l}1 \\
(6.7 \%)\end{array}$ \\
\hline $\begin{array}{l}\text { School grade } \\
\text { successfully } \\
\text { completed, mean } \\
\text { (SD) [range] }\end{array}$ & $\begin{array}{l}5 \\
.58(2.67)[0-11]\end{array}$ & $\begin{array}{l}5 \\
.91(2.18)[1-10]\end{array}$ & $\begin{array}{l}3 \\
.00(2.22)[0-8]\end{array}$ & $\begin{array}{l}5 \\
.87(2.80)[2-10]\end{array}$ \\
\hline
\end{tabular}

a - means the question is not applicable to the group.

b Two family children lived with relatives in the capital while their immediate family lived in the countryside. 


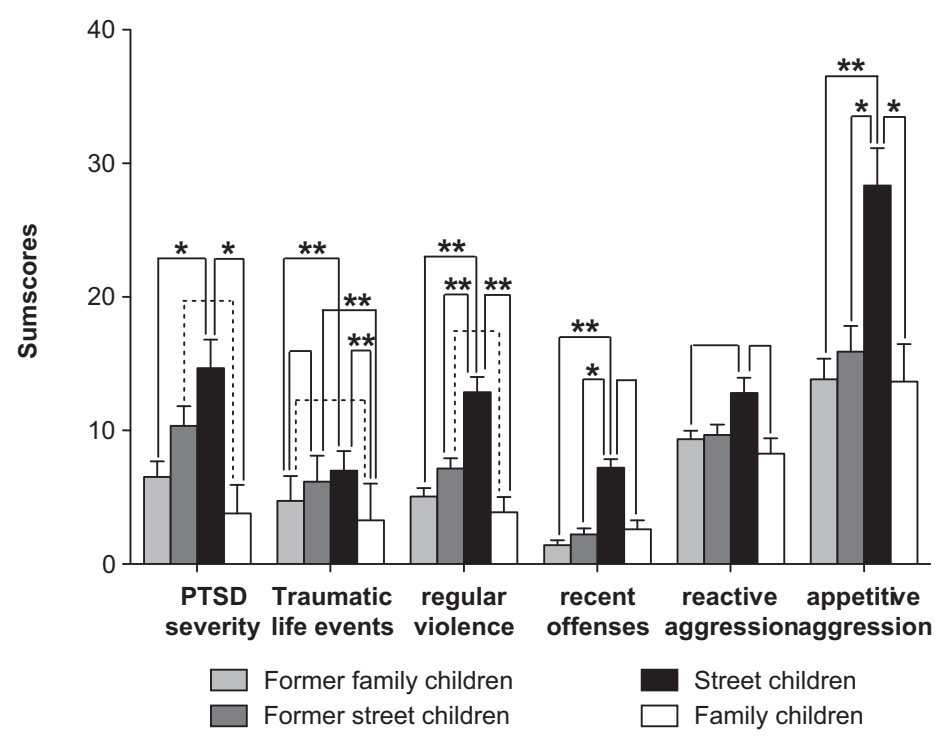

Fig. 1. Group differences in PTSD severity, traumatic life events, regularly experienced violence, recent offenses, reactive aggression and appetitive aggression. Dotted lines $(p \leq .1)$, solid lines $(p \leq .05), 1$ asterisk $\left({ }^{*} p \leq .01\right)$ and 2 asterisks $\left({ }^{* *} p \leq .001\right)$ indicate the level of significance of the differences.

and appetitive aggression $\left(F_{(3,108)}=7.25, p<.001, \eta_{p}^{2}=.17\right)$. Only the differences in reactive aggression $\left(F_{(3,108)}=3.07, p=.031\right.$, $\left.\eta_{p}^{2}=.08\right)$ had moderate effect sizes on the univariate level.

The results of the post hoc comparisons are illustrated in Fig. 1. Street children reported significantly higher values regarding all variables compared to former family children and family children. However, they differed only from the former street children in regularly experienced violence, recent offenses, and appetitive aggression. The former street children suffered somewhat more from PTSD symptoms and had experienced somewhat more regular violence than family children. Furthermore they had experienced more traumatic life events than both former family children and family children. The latter two groups differed only by tendency regarding the traumatic life events.

\section{Aggression and PTSD}

The different relationships between experienced violence, reactive aggression, appetitive aggression, and PTSD symptoms were assessed with a multiple linear regression. PTSD severity was predicted with regularly experienced violence and violence experienced in the past three months because previous analysis had revealed that both of them had a strong impact on the PTSD symptoms regardless of the number of traumatic life events. Additionally the PTSD severity was predicted with reactive aggression and appetitive aggression. One participant with no traumatic life events was excluded from the regression. Furthermore, we excluded all children with more than eight traumatic events assuming that a protective effect of appetitive aggression would become apparent only in participants with a low-to-moderate load of traumatic events. The excluded children consisted of the following: one former family child; five former street children; three street children; and two family children. In the remaining sample of 100 children with traumatic life events ranging from one to eight, appetitive aggression was negatively associated with PTSD severity $(\beta=-.227, p=.031)$ while reactive aggression and PTSD symptom severity showed a positive relationship $(\beta=.304, p=.003)$. Both the regularly experienced violence and violence experienced in the past three months contributed significantly to the explanation of the PTSD severity. The model explained $29 \%$ of the variance. Cook's distance only reached a maximum of .21, which indicated no significant influence of outliers, and thus, no outlying cases were excluded (Tabachnick \& Fidell, 2006).

\section{Aggression and recent offenses}

In order to explore how much appetitive aggression and reactive aggression contribute to the explanation of recently committed violence, we conducted a hierarchical linear regression model. In the first step we predicted the recent offenses of the children with reactive aggression. Adding appetitive aggression in the second step increased the explained variance significantly with a moderate effect size from $21 \%$ to $41 \%\left(F_{(1,109)}=38.191, p<.001, K^{2}=.25\right)$. Furthermore appetitive aggression was a much stronger predictor of recently committed offenses than reactive aggression (see Table 2 ). If taken as the only predictor, appetitive aggression explained $38 \%$ of the variance of the committed offenses.

As Cook's distance only reached a maximum of .15, indicating no significant influence of outliers, no outlying cases were excluded (Tabachnick \& Fidell, 2006). This regression model is supported by descriptions by Burundian youths of their own violent behavior: 
Table 2

Regression analysis predicting recent offenses with reactive aggression and appetitive aggression.

\begin{tabular}{llrr}
\hline Model & \multicolumn{1}{c}{ Predictors } & Beta & $p$ \\
\hline 1 & Reactive aggression & .466 & $<.001$ \\
2 & Reactive aggression & .203 & .018 \\
& Appetitive aggression & .522 & .410 \\
\hline
\end{tabular}

In the beginning I was very angry and I wanted to punish him (the thief), but then I started to enjoy beating him. I felt the need to harm him. I took a hammer and a dull nail and started to torture him. I have beaten the nail again and again in his feet. I do not even know how often I did this. Every time he was screaming. I continued all night to beat him with a stick and to torture him with the hammer and the nail. He was bleeding everywhere and cried that we would kill him. I felt joy everywhere in my body and was very satisfied. I was pleased to hurt him. I felt powerful. The feeling was like winning a football game against a very strong team. I did not want to stop. (A young man, 21 years old, describes the punishment of a thief.)

I was provoked by somebody else. I was tired and told him to stop. But he continued. Finally I became really angry and slapped him in the face. I took his shirt and slapped him again several times. He fell to the ground. I was satisfied. He was an impossible person. I was a little proud and at the same time still very angry. He tried to fight back but I continued to slap him. Finally other people separated us. His nose was bleeding. I was very satisfied. I was proud because he had misbehaved and I had corrected him. I felt strong in my arms. He wanted to continue but the others prevented him from doing so. I felt powerful and superior. I was ready to beat him up again. I was still angry but I felt also somehow happy. (A 17 year old describes a fight.)

Once a women insulted me. She tried to intimidate me and told me that she could beat me up because I had slapped her child once. I told her that she was not able to beat me up and she tried to attack me. But I made her fall in the curb and I sat myself on her. I slapped her again and again. She bled and I thought that this will be a good memory. She was bleeding out of her mouth. I felt proud, strong and powerful. I thought that I had the right to punish her because she was always disrespectful. I was happy to punish her and enjoyed it. In the meantime other people had gathered around us but no one tried to interfere. I beat her until I had enough. When she tried to intimidate me I told her I would use a machete the next time. Then I went home. I had gained the respect of everyone because this women was known to be very rude all the time. (A 13 year old describes a fight with an older women.)

\section{Discussion}

Results showed that the majority of the children and adolescents had experienced a substantial number of traumatic events. This most likely reflects the fact that the war and the subsequent insecurity even affected the children who grew up in their family environment. In line with our hypothesis, the exposure to regular violence and traumatic life events was greatest in street children, followed by former street children, former family children, and current family children. Even though not all differences were significant, the former street children were consistently the second most affected group. Hence we conclude that we included enough children from different backgrounds to guarantee sufficient variance for the regression analysis. The reactive aggression and the PTSD severity showed a similar pattern. Although the former and current family children differed significantly from the current street children, the former street children did not. The similar pattern of these two variables is in line with research suggesting that reactive aggression and PTSD are linked to each other (e.g., Marsee, 2008). However, in appetitive aggression the current street children differed from the other groups while those did not differ significantly from each other. Most likely two factors contribute to this. On average the former street children had already spent five years in the residential center and hence lived in a more controlled and somewhat safer environment with fewer opportunities to act violently than the current street children. As most of them had left the streets when they were still small children they had not committed significantly more offenses than the former family children and current family children. This explanation is in line with studies that link the development of appetitive aggression with the number of committed offenses during the lifetime (Crombach, Weierstall, Hecker, Schalinski, \& Elbert, 2013; Hecker, Hermenau, Maedl, Elbert, \& Schauer, 2012). Additionally, research with former combatants indicates that appetitive aggression diminishes to some degree when they return to a context in which violent behavior is not useful (Hermenau, Hecker, Schaal, Maedl, \& Elbert, 2013). Apparently living in the residential center does not provide many more opportunities to act violently than growing up in a family in Burundi. This idea is confirmed by the result that the children in the residential center had not committed more offenses in the past three months than the children living with families. Another reason for the latter result could be that the children in the center were very mistrustful in the beginning and expected that the information gathered by the researchers would be used to decide which child would be reintegrated into the catastrophic conditions of their families. Hence some underreporting regarding the committed offenses might be expected.

Concerning the relationship between aggression and mental illness we provided evidence that appetitive aggression and reactive aggression are linked to PTSD symptom severity in opposing directions. Although reactive aggression was elevated when children suffered from PTSD symptoms, appetitive aggression was diminished. This result is in line with both studies 
linking PTSD with reactive aggression (e.g., Connor et al., 2003) and studies reporting that appetitive aggression protects from the development of PTSD (e.g., Weierstall et al., 2011). As in those studies, the protective effect of appetitive aggression showed only if the number of traumatic events experienced by the children and youths was below a certain threshold. Apparently appetitive aggression prevents the development of PTSD symptoms. However, this holds only up to a certain threshold number of traumatic experience, beyond which PTSD overwhelms everyone.

For the first time, we provided evidence that the protective effects of appetitive aggression are not only limited to combatants but can be found in children growing up in insecure but not war-like environments. Hence appetitive aggression may reduce the risk for developing mental disorders in various kinds of violent environments. As a protective factor of last resort it prevails even when risk factors for mental ill-health and personal integrity are too many and other protective factors are too few. If an individual experiences violence as appetitive, then cues associated with violence, such as pain, screams and blood will become processed in a positive association network, rather than a fear-associated network (Elbert et al., 2010). Connecting positive feelings with cues of violent situations diminishes their impact on the already existing fear network and thereby increases the resilience of the child or the youth against violent experiences. This mechanism also explains why street boys seem to have a certain resilience against mental illness and are less affected than expected (Aptekar, 2004).

At the same time appetitive aggression was a much stronger predictor for recently committed violence than reactive aggression, although the latter still had some influence. This confirms our hypothesis that violent behavior is influenced by negative and positive emotions alike. Furthermore the results suggest that it may even be more important to focus on the emotional gain, i.e., appetitive aggression, than on reactive aggression when trying to prevent violent behavior in children and youths. Most violent situations include elements of reactive and appetitive aggression, the testimony of the youths cited above illustrates this.

Interventions aiming to reduce aggressive behavior in children and youths need to address appetitive aggression. A first step might be accepting and normalizing the existence of positive emotions in the context of violent offenses, thereby facilitating perpetrators acknowledging and dealing with them. Elbert, Hermenau, Hecker, Weierstall, and Schauer (2012) suggested an intervention aiming to break down the positive association network regarding aggression by means of narrative elaboration. Associating positive emotions, such as power, excitement and pleasure, with specific temporal and spatial cues reduces the probability of triggering them in potentially violent situations. Further approaches could aim to link these emotions to socially appropriate activities and/or provide perpetrators with relationships that reinforce non-violent behavior and trust. In a subsequent study, we thus have offered the children of the residential center treatment, the results of which will be published elsewhere.

The study has some limitations. The data presented is correlational. Consequently, our causal interpretations of the relationships between predictors and dependent variables can be challenged. For example, it could be argued that although recently committed violent acts increase appetitive aggression, appetitive aggression does not increase the probability of aggressive behavior. Previous research showed that appetitive aggression is strongly related to the number of offenses committed during the lifetime (e.g., Crombach et al., 2013) and most likely increases if acts of violence are accompanied by feelings of control, power, and enjoyment. However, it seems still very likely that an attraction toward violence increases violent behavior at the same time. Hence we expect both explanations to be true and to contribute to the cycle of violence. Furthermore it could be argued that appetitive aggression is not a protective factor but rather a coping strategy of affected individuals against PTSD. This is contradicted by the fact that healthy individuals experience appetitive aggression also. Of course, once individuals have acquired a taste for violence and suffer from PTSD, they might also use it as a coping strategy. By behaving aggressively they can replace feelings of helplessness, fear and insecurity with feelings of control, power and security. In fact this "flight into violence" might be a common coping strategy amongst mentally ill individuals as research suggests that aggressive behavior is often motivated by a need to regain control and power (Gage, 2005; Guma \& Henda, 2004). Hence appetitive aggression might be even an important factor explaining why PTSD is linked to aggressive behavior. The reactive aggression of affected individuals might be amplified by appetitive aggression as a way to cope with their helplessness and terror and to overcome traumatic stress (Schauer \& Schauer, 2010).

Another limitation of this study is the use of self-reports for aggressive behavior. The assessment of aggression, particularly appetitive aggression, is thereby potentially diminished or biased as a consequence of norms of the society and the susceptibility to giving socially desirable answers to aggression questionnaires (Blümke \& Zumbach, 2007). This might be especially true for the children in the center. They were afraid of suddenly being sent back to their families and of being abandoned to deal with their difficult life situations alone. Most of them had learned to be mistrustful of others, especially adults. Hence the need to protect themselves could have distorted their reports, and consequently the real effects of aggressive attitudes may even be underestimated in this study.

Based on the results presented we conclude that appetitive aggression develops out of feelings of power and safety with the perpetration of violence in an insecure, unpredictable and violent environment. In such circumstances the enjoyment of violence is a useful adaption and serves as a protective factor against the development of mental illness because it increases the resilience against negative consequences of violent experiences. This effect is not limited to combatants but can also be found for children growing up in insecure situations. Appetitive aggression is also a strong risk factor for future violent behavior. This result is in line with research from Hart, O'Toole, Price-Sharps, and Shaffer (2007), who found that "not having feelings of power and safety with the use of aggression and violence" (p. 377) prevents children from engaging in violent behavior. Hence preventive measures for violent behavior have to focus on appetitive aggression in order to successfully 
diminish violent behavior. This is particularly true for children who grew up in violent environments such as the streets of Bujumbura.

\section{Acknowledgements}

We thank members of the Fondation Stamm, a local NGO in Burundi, for their helpful advice and Dr. Manassé Bambonyé, Dean of the Department of Clinical Psychology of the University Lumière of Bujumbura for his support. We are most grateful to Dipl.-Psych. Judith Stöckel and our Burundian interpreters Jean-Baptiste Niyungeko, and Hervé Ntiruseseka, for helping in the conducting of the assessments.

\section{References}

Aptekar, L. (1994). Street children in the developing world: A review of their condition. Cross-Cultural Research, 28, $195-224$.

Aptekar, L. (2004). The changing developmental dynamics of children in particularly difficult circumstances: Examples of street and war-traumatized children. In U. P. Gielen, \& J. Roopnarine (Eds.), Childhood and adolescence: Cross-cultural perspectives and applications (pp. 371-411). Westport, CT: Praeger.

Blümke, M., \& Zumbach, J. (2007). Implicit and explicit measures for analyzing the aggression of computer gamers. In G. Steffgen, \& M. Gollwitzer (Eds.), Emotions and aggressive behavior (pp. 38-57). Göttingen: Hogrefe \& Huber Publishers.

Bop, C. (1990). The unwanted ones. Vie Sante, 3, 27-29.

Catani, C., Jacob, N., Schauer, E., Kohila, M., \& Neuner, F. (2008). Family violence, war, and natural disasters: A study of the effect of extreme stress on children's mental health in Sri Lanka. BMC Psychiatry, 8, 33. http://dx.doi.org/10.1186/1471-244X-8-33

Connor, D. F., Doerfler, L. A., Volungis, A. M., Steingard, R. J., \& Melloni, R. H., Jr. (2003). Aggressive behavior in abused children. Annals of the New York Academy of Sciences, 1008, 79-90.

Crombach, A., Weierstall, R., Hecker, T., Schalinski, I., \& Elbert, T. (2013). Social status and the desire to resort to violence - A study on former child soldiers in Uganda. Journal of Aggression, Maltreatment and Trauma, 22, 559-575.

Curtis, G. C. (1963). Violence breeds violence - Perhaps? American Journal of Psychiatry, 120, 386-387.

Elbert, T., Hermenau, K., Hecker, T., Weierstall, R., \& Schauer, M. (2012). FORNET: Treatment of traumatized and non-traumatized violent offenders by means of Narrative Exposure Therapy. In J. Endrass, A. Rossegger, F. Urbaniok, \& B. Borchard (Eds.), Interventionen bei Gewalt- und Sexualstraftätern. Risk-Management, Methoden und Konzepte der forensischen Therapie (Interventions for violent and sexual offenders. Risk management, methods and concepts of forensic therapeutic approaches) (pp. 255-276). Berlin, Germany: Medizinisch Wissenschaftliche Verlagsgesellschaft.

Elbert, T., Rockstroh, B., Kolassa, I.-T., Schauer, M., \& Neuner, F. (2006). The influence of organized violence and terror on brain and mind: A co-constructive perspective. In P. Baltes, P. Reuter-Lorenz, \& F. Rösler (Eds.), Lifespan development and the brain: The perspective of biocultural co-constructivism (pp. 326-349). New York, NY: Cambridge University Press.

Elbert, T., Schauer, M., Schauer, E., Huschka, B., Hirth, M., \& Neuner, F. (2009). Trauma-related impairment in children - A survey in Sri Lankan provinces affected by armed conflict. Child Abuse E Neglect, 33, 238-246.

Elbert, T., Weierstall, R., \& Schauer, M. (2010). Fascination violence - On mind and brain of man hunters. European Archives of Psychiatry and Clinical Neuroscience, 260, 100-105.

Flannery, D. J., Wester, K. L., \& Singer, M. I. (2004). Impact of exposure to violence in school on child and adolescent mental health and behavior. Journal of Community Psychology, 32, 559-573.

Fontaine, R. G. (2007). Disentangling the psychology and law of instrumental and reactive subtypes of aggression. Psychology, Public Policy, E Law, 13, $143-165$.

Ford, J. D. (2002). Traumatic victimization in childhood and persistent problems with oppositional-defiance. Journal of Aggression, Maltreatment and Trauma, $6,25-58$.

Gage, A. J. (2005). Women's experience of intimate partner violence in Haiti. Social Science E' Medicine, 61, 343-364.

Guma, M., \& Henda, N. (2004). The socio-cultural context of child abuse: A betrayal of trust. In L. Richter, A. Dawes, \& C. Higson-Smith (Eds.), Sexual abuse of young children in southern Africa (pp. 95-109). Cape Town, South Africa: Human Science Research Council Press.

Hart, J. L., O'Toole, S. K., Price-Sharps, J. L., \& Shaffer, T. W. (2007). The risk and protective factors of violent juvenile offending: An examination of gender differences. Youth Violence and Juvenile Justice, 5, 367. http://dx.doi.org/10.1177/1541204006297367

Hecker, T., Hermenau, K., Maedl, A., Elbert, T., \& Schauer, M. (2012). Appetitive aggression in former Combatants - Derived from the ongoing Conflict in DR Congo. International Journal of Law and Psychiatry, 35, 244-249. http://dx.doi.org/10.1016/j.ijlp.2012.02.016

Hecker, T., Hermenau, K., Maedl, A., Hinkel, H., Schauer, M., \& Elbert, T. (2013). Does perpetrating violence damage mental health? Differences between forcibly recruited and voluntary combatants in DR Congo. Journal of Traumatic Stress, 26, 142-148.

Hecker, T., Hermenau, K., Maedl, A., Schauer, M., \& Elbert, T. (2013). Aggression inoculates against PTSD symptom severity - Insights from armed groups in the eastern DR Congo. European Journal of Psychotraumatology, 4, 2070. http://dx.doi.org/10.3402/ejpt.v4i0.20070

Hermenau, K., Hecker, T., Ruf, M., Schauer, E., Elbert, T., \& Schauer, M. (2011). Childhood adversity, mental ill-health and aggressive behavior in an African orphanage: Changes in response to trauma-focused therapy and the implementation of a new instructional system. Child and Adolescent Psychiatry and Mental Health, 5, 29. http://dx.doi.org/10.1186/1753-2000-5-29

Hermenau, K., Hecker, T., Schaal, S., Maedl, A., \& Elbert, T. (2013). Addressing post-traumatic stress and aggression by means of narrative exposure - A randomized controlled trial with ex-combatants in the eastern DRC. Journal of Aggression, Maltreatment and Trauma, $22,916-934$. http://dx.doi.org/10.1080/10926771.2013.824057

Human Rights Watch. (2012). "You will not have peace while you are living." The escalation of political violence in Burundi. Retrieved from http://www.hrw.org

Jordans, M. J. D., Tol, W. A., Komproe, I. H., Susanty, D., \& Vallipuram, A. (2010). Development of a multi-layered psychosocial care system for children in areas of political violence. International Journal of Mental Health Systems, 4, 15. http://dx.doi.org/10.1186/1752-4458-4-15

Kempes, M., Matthys, W., de Vries, H., \& van Engeland, H. (2005). Reactive and proactive aggression in children - A review of theory findings and the relevance for child and adolescent psychiatry. European Child and Adolescent Psychiatry, 14, 11-19.

Marsee, M. A. (2008). Reactive aggression and posttraumatic stress in adolescents affected by Hurricane Katrina. Journal of Clinical Child and Adolescent Psychology, 37, 519-529.

Moretti, M. M., Obsuth, I., Odgers, C. L., \& Reebye, P. (2006). Exposure to maternal vs. paternal partner violence, PTSD and aggression in adolescent girls and boys. Aggressive Behavior, 32, 385-395.

Neuner, F., Onyut, P. L., Ertl, V., Odenwald, M., Schauer, E., \& Elbert, T. (2008). Treatment of posttraumatic stress disorder by trained lay counselors in an African refugee settlement: A randomized controlled trial. Journal of Consulting and Clinical Psychology, 76, 686-694.

Nsengiyumva, A. (2010). Doctorat sur des enfants des rues à Bujumbura. Louvain-la Neuve: Université Catholique de Louvain.

Pinheiro, P. S. (2006). World report on violence against children. Retrieved from United Nations Secretary General's Study on Violence against Children website: http://www.unicef.org

Raine, A., Dodge, K., Loeber, R., Gatzke-Kopp, L., Lynam, D., Reynolds, C., \& Liu, J. (2006). The reactive-proactive aggression questionnaire: Differential correlates of reactive and proactive aggression in adolescent boys. Aggressive Behavior, 32, 159-171. 
Schauer, M., \& Schauer, E. (2010). Trauma-focused public mental-health interventions: A paradigm shift in humanitarian assistance and aid work. In E. Martz (Ed.), Trauma rehabilitation after war and conflict. New York, NY: Springer Science+Business Media.

Shaw, J. A., \& Harris, J. J. (2003). Children of war and children at war: Child victims of terrorism in Mozambique. In R. J. Ursano (Ed.), Terrorism and disaster: Individual and community mental health interventions (pp. 41-57). New York, NY: Cambridge University Press.

Shields, A., \& Cicchetti, D. (1998). Reactive aggression among maltreated children: The contributions of attention and emotion dysregulation. Journal of Clinical Child Psychology, 27, 381-395.

Shields, A., \& Cicchetti, D. (2001). Parental maltreatment and emotion dysregulation as risk factors for bullying and victimization in middle childhood. Journal of Clinical Child Psychology, 30, 349-363.

Sommers, M. (2013). Adolescents and violence: Lessons from Burundi Discussion paper. Retrieved from Institute of Development Policy and Management website: http://www.ineesite.org

Steinberg, A. M., Brymer, M. J., Decker, K. B., \& Pynoos, R. S. (2004). The University of California at Los Angeles Post-traumatic Stress Disorder Reaction Index. Current Psychiatry Reports, 6, 96-100.

Tabachnick, B. G., \& Fidell, L. S. (2006). Using multivariate statistics (5th ed.). New York, NY: Pearson Education.

Thomas de Benitez, S. (2007). State of the world's street children: Violence. In Street children series. London, England: Consortium of Street Children.

Turnera, H. A., Finkelhor, D., \& Ormrodb, R. (2006). The effect of lifetime victimization on the mental health of children and adolescents. Social Science E Medicine, 62, 13-27.

Vitiello, B., \& Stoff, D. M. (1997). Subtypes of aggression and their relevance to child psychiatry. Journal of the American Academy of Child and Adolescent Psychiatry, 36, 307-315

Warf, C., Eisenstein, E., \& Stahl, C. (2009). Children, adolescents and war: The systematic engagement of youth in collective violence. Adolescent Medicine: State of the Art Reviews, 20, 961-980.

Weaver, C. M., Borkowski, J. G., \& Whitman, T. L. (2008). Violence breeds violence: Childhood exposure and adolescent conduct problems. Journal of Community Psychology, 36, 96-112. http://dx.doi.org/10.1002/jcop.20219

Weierstall, R., Bueno Castellanos, C. P., Neuner, F., \& Elbert, T. (2013). Relations among appetitive aggression, post-traumatic stress and motives for demobilization: A study in former Colombian combatants. Conflict and Health, 9. http://dx.doi.org/10.1186/1752-1505-7-9

Weierstall, R., \& Elbert, T. (2011). The Appetitive Aggression Scale. European Journal of Psychotraumatology, 2, 8430. http://dx.doi.org/10.3402/ejpt.v2i0.8430

Weierstall, R., \& Elbert, T. (2012). Subtypes and classification of human aggress. In J. Endrass, A. Rossegger, F. Urbaniok, \& B. Borchard (Eds.), Interventionen bei Gewalt- und Sexualstarftätern (Interventions with violent and sex offenders) (pp. 3-14). Berlin, Germany: Medizinisch Wissenschaftliche Verlagsgesellschaft.

Weierstall, R., Schaal, S., Schalinski, I., \& Elbert, T. (2011). The thrill of being violent as an antidote to trauma-related ill-health. European Journal of Psychotraumatology, 2, 6345. http://dx.doi.org/10.3402/ejpt.v2i0.6345

Weierstall, R., Schalinski, I., Crombach, A., Hecker, T., \& Elbert, T. (2012). When combat prevents PTSD symptoms - Results of a survey with former child soldiers in Northern Uganda. BMC Psychiatry, 12, 41. http://dx.doi.org/10.1186/1471-244X-12-41

Wood, J., Foy, D. W., Layne, C., Pynoos, R., \& Boyd, J. C. (2002). An examination of the relationships between violence exposure, posttraumatic stress symptomatology, and delinquent activity: An ecopathological model of delinquent behavior among incarcerated adolescents. Journal of Aggression, Maltreatment and Trauma, 6, 127-147.

World Health Organization. (2008). ICD-10: International statistical classification of diseases and related health problems (10th revised ed.). Geneva, Switzerland: World Health Organization. 